\title{
Ecological Risk Assessment of the Uses of the Organophosphorus Insecticide Chlorpyrifos, in the United States
}

\author{
John P. Giesy, Keith R. Solomon, G. Christopher Cutler, Jeffrey M. Giddings, \\ Don Mackay, Dwayne R.J. Moore, John Purdy, and W. Martin Williams
}

\section{Introduction}

As explained in the foreword, this volume of Reviews of Environmental Contamination and Toxicology is devoted to an assessment of the ecological risks posed by chlorpyrifos $(O, O$-diethyl $O$-(3,5,6-trichloro-2-pyridinyl) phosphorothioate; CAS No. 2921-88-2; CPY) as used in the United States (U.S.). CPY is a widely used organophosphorus insecticide that is available in a granular formulation for treatment in soil, or several flowable formulations that can be applied to foliage,

\author{
J.P. Giesy $(\bowtie)$ \\ Department of Veterinary Biomedical Sciences and Toxicology Centre, \\ University of Saskatchewan, 44 Campus Dr., Saskatoon, SK S7N 5B3, Canada \\ e-mail: john.giesy@usask.ca \\ K.R. Solomon \\ Centre for Toxicology, School of Environmental Sciences, University of Guelph, \\ Guelph, ON, Canada \\ G.C. Cutler \\ Department of Environmental Sciences, Faculty of Agriculture, Dalhousie University, \\ Truro, NS, Canada \\ J.M. Giddings \\ Compliance Services International, Rochester, MA, USA \\ D. Mackay \\ Trent University, Peterborough, ON, Canada \\ D.R.J. Moore \\ Intrinsik Environmental Sciences (US), Inc., New Gloucester, ME, USA \\ J. Purdy \\ Abacus Consulting, Campbellville, ON, Canada \\ W.M. Williams \\ Waterborne Environmental Inc., Leesburg, VA, USA
}


soil, or dormant trees (Solomon et al. 2014). CPY can be applied by use of aerial spraying, chemigation, ground boom or air-blast sprayers, tractor-drawn spreaders, or hand-held equipment.

Since the registration of CPY was last re-evaluated (USEPA 2004, 2008), there have been changes in how assessments of risks of chemicals used to protect agricultural crops are conducted. The amount of data available on mobility, persistence, and concentrations in the environment and toxicity of CPY to animals has increased. Most importantly, many methods and models for estimating concentrations in the environment and exposures to wildlife have improved significantly since the results of the last assessments were published (Giesy et al. 1999; Solomon et al. 2001). Also, patterns of use have changed in response to changes in cropping, pest pressure, introduction of genetically modified crop (GMO) technology, and competing pesticides. Uses of CPY are the primary determinants of the entry of CPY into the environment and its subsequent fate in the regions of use and beyond. The purpose of this paper is to provide a synopsis of uses and properties of CPY and the results risk assessments conducted for aquatic life and terrestrial biota. Mammals were not addressed in any of these risk assessments because they are less sensitive to CPY and do not have as large a potential for exposure as do birds. It was previously concluded that, if birds are not affected by a particular pattern of use, then mammals occurring in the same environment would also not be adversely affected (Solomon et al. 2001).

\section{Uses and Properties of Chlorpyrifos}

The second paper in the series reviews the current uses permitted under the current label and patterns of use in various crops (Solomon et al. 2014). The data on physical and chemical properties were reviewed and a set of consensus values were selected for use in the environmental fate assessments, which included modeling of long-range transport and assessment of bioaccumulation (Mackay et al. 2014), characterizing routes of exposure to CPY through soil, foliage, and food items in terrestrial systems (Cutler et al. 2014; Moore et al. 2014), and in surface-water aquatic systems (Giddings et al. 2014; Williams et al. 2014). Currently-registered formulations of CPY and their uses in the U.S. were the basis for the development of the exposure scenarios and the conceptual models used in assessing risks to aquatic organisms (Giddings et al. 2014; Williams et al. 2014), birds (Moore et al. 2014), and pollinators (Cutler et al. 2014). These data on use were based on the current labels and reflect changes in labels and use-patterns that have occurred since 2000. Important changes included removal of all residential and termiticide uses and changes in buffers. CPY is now registered only for use in agriculture in the U.S. but is an important tool in management of a large number of pests, mainly insects and mites. CPY is used on a wide range of crops, although applications to corn and soybeans account for $46-50 \%$ of annual use in the U.S. Estimates of total annual use in the U.S. from 2008 to 2012 range from 3.2 to $4.1 \mathrm{M} \mathrm{kg} \mathrm{y}^{-1}$, which is about $50 \%$ less than the annual use prior to 2000 . 
Large amounts of data are available on the environmental properties of CPY. These data were summarized and key values were selected for modeling fate in the environment. The vapor pressure of CPY is $1.73 \times 10^{-5}$ torr, solubility in water is $<1 \mathrm{mg} \mathrm{L}^{-1}$, and its $\log \mathrm{K}_{\mathrm{OW}}$ is 5 . The mean water-soil adsorption coefficient normalized to fraction of organic carbon in the soil $\left(\mathrm{K}_{\mathrm{OC}}\right)$ of CPY is $8.2 \times 10^{3} \mathrm{~mL} \mathrm{~g}^{-1}$. Negligible amounts enter plants via the roots, and CYP is not translocated in plants. Chlorpyrifos has short to moderate persistence in the environment as a result of several dissipation pathways that may proceed concurrently. Primary mechanisms of dissipation include volatilization, photolysis, abiotic hydrolysis, and microbial degradation. Under laboratory conditions, estimates of half-lives of CPY in soils range from 2 to $1,575 \mathrm{~d}(\mathrm{~N}=126)$, depending on properties of the soil and rate of application. As with other pesticides in soil, dissipation of CPY is often biphasic with an initial rapid dissipation followed by slower breakdown. Laboratory and field dissipation half-lives are often calculated by assuming 1st order kinetics, which might over-estimate persistence and potential for runoff into surface waters. At rates of application that were used historically for control of termites, the degradation rate is slower than at rates used in agriculture. In agricultural soils under field conditions, half-lives are shorter $(2-120 \mathrm{~d}, \mathrm{~N}=58)$ than those measured in the laboratory. Halflives for hydrolysis in water are inversely related to $\mathrm{pH}$, and range from 16 to $73 \mathrm{~d}$.

CPY is an inhibitor of acetylcholinesterase (AChE) and is potentially toxic to most animals. In vivo and in the environment, CPY is converted (activated) to chlorpyrifos oxon (CPYO), which is more reactive with AChE. Similar activation reactions occur with other phosphorothioate insecticides. Co-exposure to other chemicals can induce mixed-function oxidase enzymes responsible for activation. However, concentrations required to induce this synergism are large and co-occur rarely. Thus, this phenomenon is not an issue at environmentally relevant concentrations.

Timing of the use of CPY depends on occurrence of the pests it is used to control. There is no predominant seasonal use of CPY, although there is a somewhat greater usage in the winter for tree crops in California and greater use in summer for certain field crops (e.g., corn).

\section{Fate of Chlorpyrifos and Its Oxon in the Atmosphere and Long-Range Transport}

The third paper in the series characterized the fate of CPY and CPYO in a number of environmental compartments with a focus on transport through the atmosphere (Mackay et al. 2014). Detectable concentrations of CPY in air, rain, snow and other environmental media have been measured in North America and other locations at considerable distances from likely agricultural sources. Thus, there is a potential for long-range transport (LRT) in the atmosphere. A simple mass balance model was developed to quantify likely concentrations of CPY and CPYO at locations ranging from local sites of application to more remote locations up to hundreds of $\mathrm{km}$ distant. The characteristic travel distance (CTD) is defined as the distance at which 
$63 \%$ of the original mass of volatilized substance is degraded or deposited. Based on a conservative concentration of $\bullet \mathrm{OH}$ radicals of $0.7 \times 10^{6}$ molecules $\mathrm{cm}^{-3}$ in the atmosphere which would result in a half-life of $3 \mathrm{~h}$, the CTD for CPY was estimated to be $62 \mathrm{~km}$. At lesser concentrations of $\bullet \mathrm{OH}$ radical, such as occur at night and at lesser temperatures or in less urbanized regions, the CTD would be proportionally longer. The calculated fugacities of CPY in air and other media decrease proportionally with increasing distance from sources. This information provided an approximate prediction of downwind concentrations that are generally consistent with concentrations measured in nearby and semi-remote sites. This analysis was an improvement over previous estimates of LRT of CPY and CPYO, but a need for improved estimates of the chemical-physical properties of CPYO was identified.

The properties of CPY were assessed against criteria for classification as a persistent organic pollutant (POP) under the Stockholm convention or as persistent, bioaccumulative and toxic (PBT) under the European Community regulation EC 1107/2009 (Mackay et al. 2014). CPY and CPYO do not trigger criteria for classification as a POP or LRT under the Stockholm convention or a PB chemical under EC $1107 / 2009$. Although CPY is toxic at concentrations less than the trigger for classification as "T" under EC1107/2009, this simple trigger needs to be placed in the context of low risks to non-target organisms close to the areas of use. Overall, neither CPY nor CPYO trigger the criteria for PBT under EC 1107/2009.

CPYO is not predicted to persist in the environment, and indeed is not found in surface waters. Because CPYO is the metabolically activated toxic form of CPY, the toxicity of CPYO is implicitly measured when testing CPY. For these reasons, we concluded that additional fate studies for CPYO in the environment by either modeling or monitoring or additional studies of toxicity are not warranted. There is sufficient monitoring and toxicity testing to determine that the uncertainties in conclusions about the oxon are not large.

\section{Chlorpyrifos in Surface Water}

The fourth paper in the series characterizes the measured and modeled concentrations of CPY in surface waters of the U.S. (Williams et al. 2014). The frequencies of detection and 95th centile concentrations of CPY in surface waters in the U.S. have decreased more than five-fold between 1992 and 2010. Detections of CPY in 1992-2001 ranged from 10 to 53\% of samples. In the period 2002-2010, detections were 7 to $11 \%$. The 95 th centile concentrations ranged from 0.007 to $0.056 \mu \mathrm{g} \mathrm{L}^{-1}$ in 1992-2001 and 0.006 to $0.008 \mu \mathrm{g} \mathrm{L}^{-1}$ in 2002-2010. The greatest frequency of detections and 95 th centile concentrations occurred in undeveloped and agricultural land-use classes.

The two classes of land-use with the most urban land (urban and mixed) had the smallest frequency of detections and 95th centile concentrations. This result is consistent with cessation of sale of CPY-based products for residential uses in December 2001. Overall, the U.S. Geological Survey (USGS) database with the greatest 
number of samples (more than 10,000) and broadest geographical representation showed that CPY was detected in 9\% of samples between 2002 and 2010 and that $95 \%$ of samples contained less than $0.007 \mu \mathrm{g} \mathrm{L}^{-1}$, and the maximum was $0.33 \mu \mathrm{g} \mathrm{L}^{-1}$. Regional databases maintained by the California Department of Pesticide Regulation (CDPR) and Washington State Department of Ecology (WDOE), which were more focused on areas of pesticide use than the USGS database, had more frequent detections (13-17\%) and greater concentrations (95th centiles $0.010-0.3 \mu \mathrm{g} \mathrm{L}^{-1}$ ). No detections were reported in the 42 samples of saltwater and few data (total=123) were available for analyses of CPY in sediments. Only three sediments had concentrations above the limit of detection ( $\mathrm{LOD}=2 \mu \mathrm{g} \mathrm{kg}^{-1} \mathrm{dwt}$ ) and the largest concentration detected was $59 \mu \mathrm{g} \mathrm{kg}^{-1}$. Overall, the results indicate decreasing trends in concentrations of CPY that are explained largely by corresponding decreases in annual use and removal of residential uses from the labels.

Detections of CPYO were infrequent and all were less than the level of quantitation $\left(\mathrm{LOQ}=0.011-0.054 \mu \mathrm{g} \mathrm{L}^{-1}\right)$. Only 25 detections were reported in a total of 10,375 samples analyzed between 1999 and 2012. The low frequency of detection and the small concentrations found are consistent with the reactivity of CPYO and its shorter hydrolysis half-life (Mackay et al. 2014). These findings suggest that concerns for the presence of CPYO in drinking-water (USEPA 2011a), where CPYO may be formed during chlorination, are not transferable to surface waters.

Collectively, the monitoring data on CPY provide relevant insight for quantifying the range of concentrations in surface waters. However, relatively few monitoring programs have sampled at a frequency sufficient to quantify the temporal pattern of exposure. Therefore, numerical models were used to characterize concentrations of CPY in water and sediment for three representative high exposure environments in the U.S. (Williams et al. 2014). The environments were selected by parallel examination of patterns and intensity of use across the U.S. Simulations were conducted to understand relative vulnerabilities of CPY to runoff with respect to soil, and weather variability across the U.S. From the analyses, three geographical regions, one each in central California, southwestern Georgia, and the Leelanau peninsula of Michigan, were identified as having greater potential exposure to CPY and were used as focal scenarios for detailed modeling.

A small watershed, defined as a 3 rd order stream, was selected from each region based on high density of cropland eligible for receiving applications of CPY according registered uses. The modeling used two versions of PRZM, one (V-3.12.2) for modeling applications to field-crops and the other (WinPRZM), which was modified for use of CPY in fields irrigated by flood and furrow. Additional models used were EXAMS, AgDRIFT ${ }^{\circledR}$, and SWAT. Models were configured for each watershed and simulated for up to $30 \mathrm{yr}$ of consecutive use of CPY using historical weather records for those geographical areas of the country. Daily mean concentrations of CPY in water and sediment from runoff, erosion, and drift sources were predicted at the outlet of the watersheds. Conservative assumptions were used in the configuration of the Georgia and Michigan watersheds. For example, all eligible crop acreage in each watershed was assumed to be treated, and the soil properties and number and frequency of applications of CPY were those of the use pattern that produced 
the greatest exposure estimates. Model simulations for Orestimba Creek in California used actual reported applications of CPY, but field-specific management practices were not represented in the simulations. Two half-lives for aerobic soil metabolism of CPY in soil, 28 and $96 \mathrm{~d}$, were selected for the purposes of modeling. These half-lives conservatively represent the first and second phases of bi-phasic degradation in aerobic soil metabolism studies.

Estimated concentrations of CPY in water were in general agreement with ambient monitoring data from 2002 to 2010. Maximum daily concentrations predicted for the watersheds a in California, Georgia, and Michigan were 3.2, 0.041, and $0.073 \mu \mathrm{g} \mathrm{L}^{-1}$, respectively, with the 28 -d aerobic soil metabolism half-life and 4.5, 0.042 , and $0.122 \mu \mathrm{g} \mathrm{L}{ }^{-1}$, respectively, with the $96-\mathrm{d}$ soil half-life. These estimated values compared favorably with maximum concentrations measured in surface water, which ranged from 0.33 to $3.96 \mu \mathrm{g} \mathrm{L}^{-1}$. For sediments, the maximum daily concentrations predicted for the watersheds in California, Georgia, and Michigan were $11.2,0.077$, and $0.058 \mu \mathrm{g} \mathrm{kg}^{-1} \mathrm{dwt}$, respectively, with the 28 -d half-life, and 22.8, 0.080, and $0.087 \mu \mathrm{g} \mathrm{kg}^{-1}$, respectively, with the 96-d soil half-life. Twelve detections out of 123 analyses (10\%) were contained in the USGS, CDPR, and WDOE databases with concentrations reported from $<2.0$ to $19 \mu \mathrm{g} \mathrm{kg}^{-1}$, with the exception of one value reported at $58.6 \mu \mathrm{g} \mathrm{kg}^{-1}$. Again, the modeled values compared favorably with measured values.

Duration and recovery intervals between peak concentrations of CPY influence the potential for recovery from sublethal exposures in aquatic organisms. Recovery intervals were characterized by using threshold values derived from toxicity data. Based on modeling with the 28-d half-life value, no toxicologically significant exposure-recovery events were identified in the focal watersheds in Georgia and Michigan. Using the 96-d half-life value, three exposure-recovery events of $1 \mathrm{~d}$ duration only were identified in the Michigan focal watershed. Frequency of significant events was greater in the focus watershed from California and the probability of shorter recovery events was greater. However, even in the worst-case focuswatershed in California the median duration was $1 \mathrm{~d}$.

\section{Risks of Chlorpyrifos to Aquatic Organisms}

The fifth paper in this series addressed the risks of CPY to aquatic organisms. In contrast to the previous lower-tier assessments that indicated potential adverse effects in aquatic organisms (Giesy et al. 1999), this paper relied on higher and more refined tiers of risk assessment. Effects of CPY on aquatic organisms were evaluated by comparing measured or modeled concentrations of CPY in aquatic environments to species sensitivity distributions (SSDs), cosm no observed ecologically adverse effect concentrations $\left(\mathrm{NOAEC}_{\mathrm{eco}}\right.$ ), or individual toxicity values where sufficient data to derive a SSD were not available (Giddings et al. 2014). Toxicity data included in the SSDs were all of high quality. The ranges for acute toxicity endpoints for 23 species of crustaceans ranged from 0.04 to $457 \mu \mathrm{g} \mathrm{L}^{-1}$; for 18 species 
of aquatic insects, from 0.05 to $>300 \mu \mathrm{g} \mathrm{L}^{-1}$; and for 25 species of fish, from 0.53 to $>806 \mu \mathrm{g} \mathrm{L}^{-1}$. The concentrations affecting $5 \%$ of species (HC5) derived from the SSDs were $0.034,0.091$, and $0.820 \mu \mathrm{g} \mathrm{L}^{-1}$ for crustaceans, insects, and fish, respectively. Limited toxicity data for amphibians suggested that they were less sensitive to $\mathrm{CPY}$ than fish. The $\mathrm{NOAEC}_{\mathrm{eco}}$ in 16 micro- and meso-cosm studies conducted in a variety of climatic zones was consistently close to $0.1 \mu \mathrm{g} \mathrm{L}^{-1}$. These results indicated that measured concentrations of CPY in surface waters (see Williams et al. 2014) are rarely greater than the thresholds for acute toxicity to even the most sensitive aquatic species. Comparison of limited toxicity data for benthic organisms to measured concentrations of CPY in sediments suggested de minimis risks. These conclusions are consistent with the small number (4) of kills of fish and/or invertebrates reported for use of CPY in U.S. agriculture between 2002 and 2012. The four incidents over that period of time were the result of misuse.

Analysis of risks from measured exposures showed that the decline in CYP concentrations in surface waters after labeled use-patterns changed in 2001 resulted in decreased risks for crustaceans, aquatic stages of insects, and fish. A probabilistic analysis of 96-h time-weighted mean concentrations, predicted by use of model simulation for three focus-scenarios selected for regions of more intense use of CPY and vulnerability to runoff, showed that risks from individual and repeated exposures to CPY in the Georgia and Michigan watersheds were de minimis. Risks from individual exposures in the intense-use scenario from California were de minimis for fish and insects. Risk was small for crustaceans, which are the most sensitive class of organisms.

Risks from repeated exposures in the California intense-use scenario were judged not to be ecologically relevant for insects and crustaceans, but there were some risks to fish. Limited data show that CPYO is of similar toxicity to the parent compound. Concentrations of CPYO in surface waters are smaller than those of CPY and less frequently detected (Williams et al. 2014). Risks for CPYO in aquatic organisms were found to be de minimis.

Limited data on recovery of AChE activity after inhibition with CPY suggested that conservative intervals between sublethal exposures of 2 weeks for arthropods and 4-8 weeks for fish would be sufficient to mitigate against cumulative toxicity. In the focus scenarios in Michigan and Georgia, the likelihood of cumulative toxicity was very small, although some cumulative toxicity might occur in the high-use focus scenario in California. Lack of good information on recovery of AChE in relevant species of fish and arthropods was identified as a source of uncertainty.

\section{Risks of Chlorpyrifos to Birds}

The sixth paper in this series (Moore et al. 2014) evaluated the risks of CPY to birds and built upon past assessments of CPY, including the most recent EPA re-registration assessment (USEPA 1999), and a refined probabilistic assessment of risk to birds by Solomon et al. (2001). Since these assessments were completed, there have 
been a number of amendments to the label. These included reductions in single and seasonal application rates, reductions in number of applications per season, and increases in minimum re-treatment intervals (USEPA 2009). These changes and their effects on risk to birds were addressed in this paper (Moore et al. 2014).

Refined risk assessments for birds exposed to CPY were conducted for a range of current use patterns for each formulation in the U.S. The assessments relied on focal bird species that commonly occur in and around areas where CPY might be applied and for which adequate data were available to quantify their foraging behavior and diets.

A refined version of Liquid Pesticide Avian Risk Assessment Model (LiquidPARAM) was developed for the assessment of the risks of repeated uses of flowable formulations of CPY. Flowable formulations of CPY are registered for a variety of field and tree crops in the U.S. Focal species of birds associated with these crops were selected for inclusion in the model. The major routes of exposure for birds to flowable CPY were consumption of treated dietary items and drinking water. For acute exposure, LiquidPARAM was used to estimate the maximum retained dose in each of 20 birds on each of 1,000 treated fields over the 60-d period following initial application to account for multiple applications. For each bird, the standard normal $\mathrm{Z}$ score for the maximum retained dose was determined from the appropriate probit dose-response curve and was then compared to a randomly drawn value from a uniform distribution with a range of 0 to 1 to determine whether the bird survived or died. For species lacking acceptable acute oral toxicity data (all focal species except northern bobwhite and red-winged blackbird), a SSD approach was used to generate hypothetical dose-response curves assuming high, median and low sensitivity to CPY. For acute risk, risk curves were generated for each use pattern and exposure scenario. The risk curves show the relationship between exceedance probability and percent mortality.

The results of the LiquidPARAM modeling indicated that flowable CPY poses an acute risk to some bird species, particularly those species that are highly sensitive and forage extensively in crops with large maximum application rates (e.g., grapefruit and orange; $6.3 \mathrm{~kg}$ a.i. ha ${ }^{-1}$ ). Overall, most species of birds would not experience significant mortality as a result of exposure to flowable CPY. The results of a number of field studies conducted in the U.S. and EU at application rates similar to those on the Lorsban ${ }^{\circledast}$ Advanced label indicated that flowable CPY rarely causes avian mortality and suggest that LiquidPARAM is likely over-estimating acute risk to birds for flowable CPY. A lack of well-documented bird-kill incidents associated with normal use since 2002 support the conclusions of the field studies. Of the two bird-kill incidents reported between 2002 and 2009, one was from a misuse and the other lacked sufficient information to make a determination of causality.

For estimating chronic exposure risks, the maximum average total daily intake was compared to the chronic no-observed-effect-level (NOEL) and lowest-observedeffect-level (LOEL) from the Mallard. The probabilities of exceeding the LOEL were very small, thus indicating that CPY is not a chronic risk concern for birds.

Risks resulting from the use of granular CPY were estimated using the Granular Pesticide Avian Risk Model (GranPARAM) model. Granular CPY is registered for 
a wide variety of field and row crops under the trade name Lorsban ${ }^{\circledR} 15 \mathrm{G}$. Consumption of granular pesticides is a route of exposure that is specific to birds. Grit is dietary requirement of many birds to aid in digestion of hard dietary items such as seeds and insects. Because granules of CPY are in the same size range as natural grit particles that are consumed by birds, there is a potential for birds to mistakenly ingest granular CPY instead of natural grit. The GranPARAM model accounts for the proportion of time that birds forage for grit in treated fields, relative proportions of natural grit versus pesticide granules on the surface of treated fields, rates of ingestion of grit, attractiveness of pesticide granules relative to natural grit, variability in rates of ingestion of grit, foraging behavior between birds within a focal species, and variability in soil composition between fields for the selected use pattern. Analysis of a wide variety of use patterns of the granular formulation found that CPY posed little risk to bird species that frequent treated fields immediately after application. The predictions of the model were consistent with the results of several avian field studies conducted with Lorsban $15 \mathrm{G}$ at application rates similar to or exceeding maximum application rates on the label.

\section{Risks to Pollinators}

The seventh and last paper in this series used a tiered approach to assess risks posed by CPY to insects that serve as pollinators (Cutler et al. 2014). The assessment focused on bees, although other groups of insects were also considered. Because there have been recent reports of adverse effects of some pesticides on pollinators, assessing risks of pesticides to pollinators is an important topic. A recent SETAC workshop (Fischer and Moriarty 2011) proposed changes to the assessment process (USEPA 2011b), and these served as guidance for this assessment.

Pollinators are important for both natural and agricultural ecosystems (Cutler et al. 2014). In the U.S., production of crops that require or benefit from pollination by the European honey bee, Apis mellifera L. (Apidae) has been estimated to have a monetary value greater than $\$ 15$ billion annually, while the value of non-Apis pollinators to crop production is estimated to be more than $\$ 11$ billion.

CPY is considered to be highly toxic to honey bees by direct contact exposure. However, label precautions and good agricultural practices prohibit application of CPY when bees are flying and/or when flowering crops or weeds are present in the treatment area. Therefore, the risk of CPY to pollinators through direct contact exposure should be small. The primary routes of exposure for honey bees are dietary and contact with flowers that were sprayed during application and remain available to bees after application.

The main pathways for secondary exposure to CPY are through pollen and nectar brought to the hive by forager bees and the sublethal body burden of CPY carried on forager bees. Foraging for other materials, including water or propolis, are not important routes of exposure. Because adult forager honey bees are most exposed, they are expected to be most at risk compared to other life stages and castes of 
honey bees in the hive. Although there were data on the acute oral toxicity of CPY to honeybees, this was not the case for non-Apis pollinators, where no data on toxicity or exposures were found and risks could not evaluated.

An assessment of concentrations reported in pollen and honey from monitoring in North America indicated that there was little risk of acute toxicity from CPY through consumption of these food sources. Several models were also used to estimate upper-bound exposure of honey bees to CPY through consumption of water from puddles or dew. All models suggest that the risk of CPY is minimal for this pathway. Laboratory experiments with field-treated foliage, and semi-field and field tests with honey bees, bumble bees, and alfalfa leaf-cutting bees indicate that exposure to foliage, pollen, and/or nectar is hazardous to bees up to $3 \mathrm{~d}$ after application of CPY to a crop. Pollinators exposed to foliage, pollen, or nectar after this time should be minimally affected.

Overall, the rarity of reported bee kill incidents involving CPY indicates that there is compliance with the label precautions and good agricultural practice with the product is the norm in North American agriculture. We concluded that the use of CPY in North American agriculture does not present an unacceptable risk to honeybees, provided label directions and good agricultural practices are followed. The lack of data on toxicity of and exposures to CPY in non-Apis pollinators was identified as an uncertainty. However, this issue is not specific to CPY and applies to all foliar-applied insecticides.

Acknowledgments The authors of the papers thank Jeff Wirtz of Compliance Services International, Julie Anderson of the University of Saskatchewan; J. Mark Cheplick, Dean A. Desmarteau, Gerco Hoogeweg, William J. Northcott, and Kendall S. Price, all of Waterborne Environmental for their contributions. We also acknowledge Yuzhou Luo of the California Department of Pesticide Regulation for providing the SWAT dataset for the Orestimba Creek watershed that was developed when he was associated with the University of California-Davis. We also thank Lou Best, Larry Brewer, Don Carlson of FMC Corporation, Dylan Fuge from Latham and Watkins LLP, and Nick Poletika and Mark Douglas from Dow AgroSciences for their contributions to the assessment of risks to birds. We thank the anonymous reviewers of the papers for their suggestions and constructive criticism. This independent evaluation was funded by Dow AgroSciences. Prof. Giesy was supported by the Canada Research Chair program, a Visiting Distinguished Professorship in the Department of Biology and Chemistry and State Key Laboratory in Marine Pollution, City University of Hong Kong, the 2012 "High Level Foreign Experts" (\#GDW20123200120) program, funded by the State Administration of Foreign Experts Affairs, the P.R. China to Nanjing University and the Einstein Professor Program of the Chinese Academy of Sciences.

Open Access This chapter is distributed under the terms of the Creative Commons Attribution Noncommercial License, which permits any noncommercial use, distribution, and reproduction in any medium, provided the original author(s) and source are credited.

\section{References}

Cutler GC, Purdy J, Giesy JP, Solomon KR (2014) Risk to pollinators from the use of chlorpyrifos in the United States. Rev Environ Contam Toxicol 231:219-265

Fischer D, Moriarty T (2011) Pesticide risk assessment for pollinators: summary of a SETAC Pellston Workshop. Society of Environmental Toxicology and Chemistry, Pensacola, FL 
Giddings JM, Williams WM, Solomon KR, Giesy JP (2014) Risks to aquatic organisms from the use of chlorpyrifos in the United States. Rev Environ Contam Toxicol 231:119-162

Giesy JP, Solomon KR, Coates JR, Dixon KR, Giddings JM, Kenaga EE (1999) Chlorpyrifos: ecological risk assessment in North American aquatic environments. Rev Environ Contam Toxicol 160:1-129

Mackay D, Giesy JP, Solomon KR (2014) Fate in the environment and long-range atmospheric transport of the organophosphorus insecticide, chlorpyrifos and its oxon. Rev Environ Contam Toxicol 231:35-76

Moore DRJ, Teed RS, Greer C, Solomon KR, Giesy JP (2014) Refined avian risk assessment for chlorpyrifos in the United States. Rev Environ Contam Toxicol 231:163-217

Solomon KR, Giesy JP, Kendall RJ, Best LB, Coats JR, Dixon KR, Hooper MJ, Kenaga EE, McMurry ST (2001) Chlorpyrifos: ecotoxicological risk assessment for birds and mammals in corn agroecosystems. Human Ecol Risk Assess 7:497-632

Solomon KR, Williams WM, Mackay D, Purdy J, Giddings JM, Giesy JP (2014) Properties and uses of chlorpyrifos in the United States. Rev Environ Contam Toxicol 231:13-34

USEPA (1999) Reregistration eligibility science chapter for chlorpyrifos: fate and environmental risk assessment chapter. United States Environmental Protection Agency, Washington, DC

USEPA (2004) Overview of the ecological risk assessment process in the office of pesticide programs: endangered and threatened species effects determinations. United States Environmental Protection Agency, Office of Prevention, Pesticides, and Toxic Substances, Office of Pesticide Programs, Washington, DC

USEPA (2008) Registration review—preliminary problem formulation for ecological risk and environmental fate, endangered species and drinking water assessments for chlorpyrifos. United States Environmental Protection Agency, Office of Pesticide Programs, Washington, DC

USEPA (2009) Chlorpyrifos final work plan. Registration review. United States Environmental Protection Agency, Office of Pesticide Programs, Washington, DC

USEPA (2011a) Revised chlorpyrifos preliminary registration review drinking water assessment. United States Environmental Protection Agency, Office of Chemical Safety and Pollution Prevention, Washington, DC. PC Code 059101 http://www.epa.gov/oppsrrd1/registration review/chlorpyrifos/EPA-HQ-OPP-2008-0850-DRAFT-0025\%5B1\%5D.pdf

USEPA (2011b) Interim guidance on honey bee data requirements. United States Environmental Protection Agency, Environmental Fate and Effects Division, Office of Pesticide Programs

Williams WM, Giddings JM, Purdy J, Solomon KR, Giesy JP (2014) Exposures of aquatic organisms to the organophosphorus insecticide, chlorpyrifos resulting from use in the United States. Rev Environ Contam Toxicol 231:77-118 